\title{
PREVALENCIA DE COMORBILIDADES CARDIOVASCULARES $Y$ RESPIRATORIAS EN PACIENTES CON CÁNCER DE PULMÓN EN HOSPITAL UNIVERSITARIO DE SANTANDER.
}

Julián Osma Hurtado, Felix Rangel Miranda, Ana Maria Garcia, Maria Angélica Chacón, Fabio Bolivar Grimaldos, Javier Enrique Fajardo Rivero, Tania Mendoza Herrera. Universidad Industrial de Santander, Grupo de investigación MEDITA, Bucaramanga.

\section{INTRODUCCIÓN}

La presencia de comorbilidades cardiorrespiratorias en pacientes con cáncer de pulmón puede aumentar el riesgo de complicaciones y mortalidad. Resulta necesario identificarlas para tratarlas adecuada y oportunamente.

\section{OBJETIVO}

Describir la prevalencia de comorbilidades cardiorrespiratorias en pacientes con cáncer de pulmón y su relación con factores de riesgo conocidos en nuestra población.

\section{MATERIALES Y METODOS}

Estudio observacional tipo corte transversal, muestreo no probabilístico en pacientes con diagnóstico de cáncer de pulmón (2008-2018) en un hospital de III nivel de Bucaramanga.

\section{RESULTADOS}

N: 247. Prevalencia masculina $(61,94 \%)$ con edad promedio de $67.76(+/-11.63$ años) y una mayor probabilidad de relación con comorbilidad cardiorrespiratoria a mayor edad (cardiovascular: $>70$ años; OR 3.34 ; p:0.000; respiratoria: $>65$ años; OR 2.11; p:0.006). Exposición a biomasa (OR 1.92 ; p:0.01) con predominancia femenina $(67,02 \%)$ y tabaquismo severo $(>75 \%)$ por índice tabáquico $>35$ paq/año, sin relación significativa por área.
La prevalencia de comorbilidades cardiovasculares fue de $40.08 \%$ y la prevalencia de comorbilidades respiratorias fue de 48.99 .

\section{COMORBILIDADES CARDIOVASCULARES}

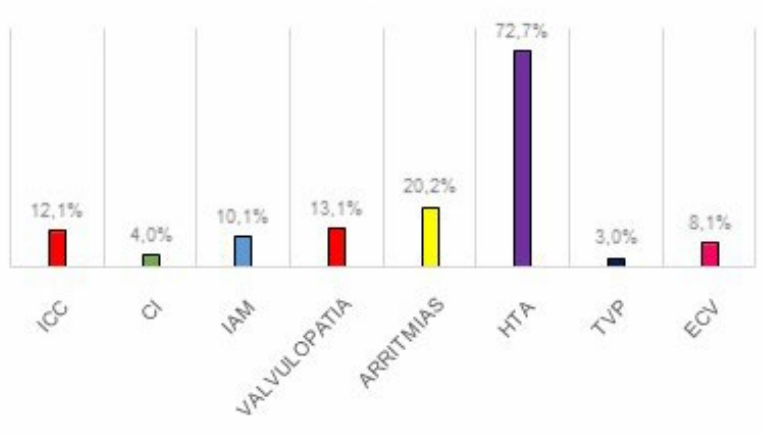

\section{COMORBILIDADES RESPIRATORIAS}

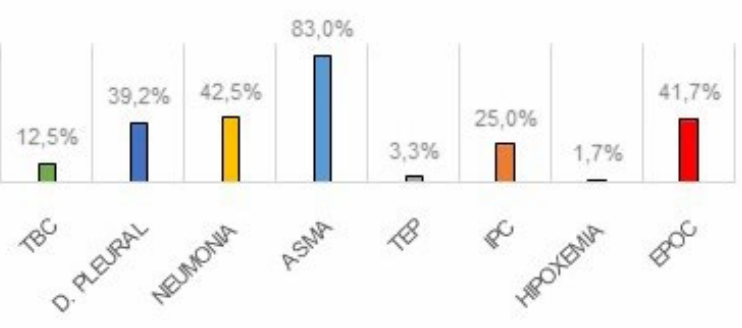

\section{CONCLUSIONES}

La principal comorbilidad cardiovascular reportada fue la hipertensión arterial, seguida por arritmias, cardiopatias valvulares e insuficiencia cardiaca. En comorbilidades respiratorias se encontraron neumonia, EPOC, y derrame pleural relacionadas con tabaquismo como factor de riesgo. Además, se observó una mayor prevalencia en exposición a biomasa en mujeres, siendo un factor a considerar en nuestra población.

\section{REFERENCIAS}

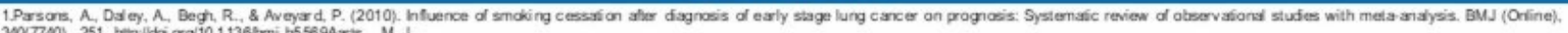

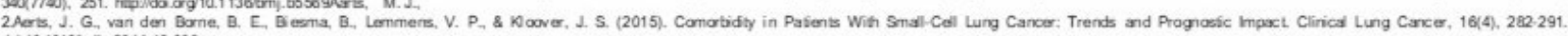
da: 10.1016 ; dle 2014.12 .003

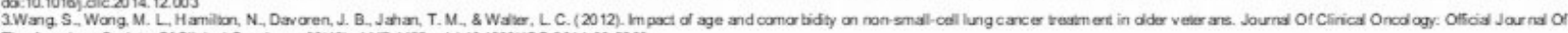

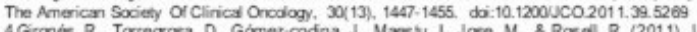

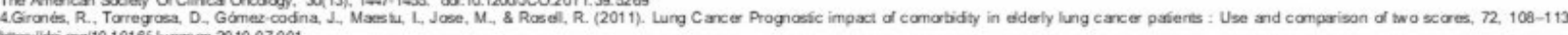

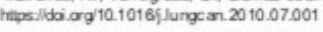

